Artigo Original

\title{
Racismo e participaçáo social na universidade: experiências de estudantes negras em cursos de saúde
}

\author{
Racism and social participation in the university: experiences of black \\ female students in health-related programs
}

Ana Cristina de Oliveira Valério ${ }^{\mathrm{a}}$ (D), Waldez Cavalcante Bezerra ${ }^{\mathrm{b}}$ (D), Vanessa Silva dos Santos (D), Jaime Daniel Leite Junior $^{d}$ (D), Magno Nunes Farias ${ }^{\mathrm{e}}$ (D), Salete Maria Bernardo dos Santos ${ }^{\mathrm{b}}$ (D)

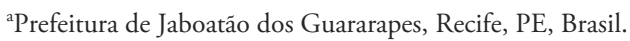

${ }^{\text {b} U n i v e r s i d a d e ~ E s t a d u a l ~ d e ~ C i e ̂ n c i a s ~ d a ~ S a u ́ d e ~ d e ~ A l a g o a s ~-~ U n c i s a l, ~ M a c e i o ́, ~ A L, ~ B r a s i l . ~}$

'Universidade Federal da Bahia - UFBA, Salvador, BA, Brasil.

${ }^{\mathrm{d} U n i v e r s i d a d e ~ F e d e r a l ~ d e ~ S a ̃ o ~ C a r l o s ~-~ U F S C a r, ~ S a ̃ o ~ C a r l o s, ~ S P, ~ B r a s i l . ~}$

eUniversidade de Brasília - UnB, Ceilândia, DF, Brasil.

Como citar: Valério, A. C. O., Bezerra, W. C., Santos, V. S., Leite Junior, J. D., Farias, M. N., \& Santos, S. M. B. (2021). Racismo e participação social na universidade: experiências de estudantes negras em cursos de saúde. Cadernos Brasileiros de Terapia Ocupacional, 29, e3007. https://doi.org/10.1590/2526-

8910.ctoAO2278

\begin{abstract}
Resumo
Indicadores educacionais do Brasil mostram uma sensível elevação da participação de mulheres negras no Ensino Superior. Porém, quando se trata de cursos considerados de alto prestígio, elas se encontram ainda mais em desvantagem. Essa tendência se expressa em seu cotidiano, demandando dessas estudantes um esforço adicional para superar o racismo. A pesquisa objetivou compreender os impactos do racismo na participação social de estudantes negras na universidade e as suas formas de enfrentamento. Trata-se de um estudo qualitativo, realizado em uma universidade pública do estado de Alagoas, adepta apenas do sistema de cotas sociais. A produção de dados ocorreu por meio de grupo focal com seis estudantes negras de três cursos da área da saúde da universidade, que se autodeclararam negras/pretas ou negras/pardas. Os dados produzidos foram analisados por meio da técnica de análise temática, sendo apresentados e discutidos com base em três categorias: dificuldades relacionadas ao acesso e permanência na universidade; expressóes do racismo no cotidiano universitário; e estratégias de enfrentamento ao racismo. Revelaram-se dificuldades em seu ingresso e trajetória no Ensino Superior, sendo atravessadas pelos marcadores de gênero, raça e classe. Reforça-se a necessidade das açôes afirmativas no contexto universitário; sugere-se o aprofundamento teórico e a reflexão acerca do tema.
\end{abstract}

Palavras-chave: Mulheres; Racismo; Educação Superior. 


\begin{abstract}
$\underline{\text { Abstract }}$
Educational indicators from Brazil show a sensible increase in the participation of black women in higher education; however, when it comes to courses considered to be of high prestige, they are even more at a disadvantage. This tendency is expressed in their everyday lives, demanding from these female students an additional effort to overcome racism. This research aimed to understand the impacts of racism on the social participation of black female undergraduate students in the university and the ways of facing it. This is a qualitative study, carried out at a public university in the state of Alagoas, which adheres only to the social quota system. The data production has occurred through a focus group with six black female undergraduate students, from three distinct health undergraduate courses by the university, who self-declared blacks. The data produced were analyzed using the thematic analysis technique, being presented and discussed from three categories: Difficulties related to access and stay at the university; Expressions of racism in university everyday life; and Strategies to fight against racism. Difficulties in the entry and trajectory of these black women in higher education were perceived, which were crossed by the markers of gender, race, and class. The need for affirmative policies in the university context is reinforced and theoretical deepening and reflection on the theme is suggested.
\end{abstract}

Keywords: Women; Racism; Education, Higher.

\title{
Introdução
}

Os caminhos históricos percorridos pela educação superior no Brasil são atravessados por contextos socioeconômicos, tornando-se notório que, desde as suas primeiras formulações, tratava-se de um espaço destinado a poucos, visando privilegiar as elites sociais (Carneiro \& Bridi, 2020). De início tardio, no Brasil Colônia, surgem as primeiras experiências de Ensino Superior no país, ministradas por religiosos, sob a direção dos Jesuítas, limitadas aos cursos de filosofia e teologia, colocados à serviço da metrópole. Segundo Rodrigues (2011, p. 45), “[...] só com a vinda da família imperial portuguesa são criados os primeiros cursos de engenharia, medicina, direito $\mathrm{e}$ agronomia”. Esta iniciativa teve como objetivo formar burocratas para o Estado e especialistas para a produção, iniciando a formação de profissionais liberais, filhos de fazendeiros que integravam a elite do poder (Roubião, 2013).

Esse sistema deixava à margem brancos livres e pobres - por não terem recursos para pagar os professores quando o Estado não o fazia -, negros livres, escravizados e mestiços, sustentado no discurso de que negro é uma raça inferior, propensa ao vício, ao crime e inimigos do progresso (Roubiáo, 2013); logo, o investimento em educação seria um desperdício. Apartados do ambiente educacional, uma massa expressiva de negros foi submetida a trabalhos braçais e precarizados, ficando distantes da educaçáo básica e, consequentemente, do Ensino Superior (Christillino, 2015). 
O fim da escravização dos negros no Brasil ${ }^{1}$ não significou a garantia de políticas que os integrassem socialmente ao novo regime de organização de trabalho e educação. Todas as instituiçóes e entidades se isentaram de quaisquer responsabilidades de manutenção e segurança dos libertos (Fernandes, 1965). Até os dias atuais, perduram marcas desse sistema, uma vez que poucos são os negros nas universidades.

No começo da década de 1990, os Movimentos Negros, juntos a outros Movimentos Sociais, articularam-se para pressionar o governo na resolução dos problemas que os atingiam. Dentre as ações e reivindicaçóes, destaca-se aqui a luta pela implementação de políticas públicas afirmativas, visando ao acesso de estudantes negros e egressos de escolas públicas ao Ensino Superior.

Nesta perspectiva, somente por volta de 2000, chega ao Brasil a política de ação afirmativa, criada nos Estados Unidos da América na década de 1960, visando diminuir e amenizar as desigualdades sociais e econômicas entre brancos e negros. A implementação desta política para negros se fortaleceu por meio da denominada Lei de cotas, $\mathrm{n}^{\circ}$ 12.711/2012, sancionada em 29 de agosto de 2012 (Brasil, 2012). Sua votação envolveu um extenso debate, com diferentes perspectivas. Porém, a decisão favorável estabeleceu reserva de vagas nas Instituiçôes Federais de Ensino Superior (IFES) para estudantes de baixa renda, pretos, pardos e indígenas e oriundos de escolas públicas (Jesus \& Gomes, 2014; Paixão et al., 2010).

Apesar da referida Lei representar um avanço significativo da população negra em relação ao acesso ao Ensino Superior, muito ainda precisa ser feito para alcançar de fato uma igualdade racial no Brasil, dada a execução tardia de políticas compensatórias (Paixáo et al., 2010).

Nessa dinâmica histórica, é necessário evidenciar que a questão racial é estrutural. Almeida (2018, p. 15) aponta que o racismo estrutural "[...] é um elemento que integra a organização econômica e política da sociedade [...]. O racismo fornece o sentido, a lógica e tecnologia para as formas de desigualdade e violência que moldam a vida social contemporânea". Uma de suas faces é o racismo institucional, predeterminando quais indivíduos serão "percebidos" pelas instituições e seus serviços e quais devem ser visibilizados, racializando o acesso ao mercado de trabalho e privando alguns do acesso à educação e às posiçôes de prestígio social (Almeida \& Alves, 2011; Almeida, 2018).

Nesse sentido, o racismo institucional é um dos mecanismos pelo qual o racismo estrutural se reproduz e manifesta seu poder de manutenção de privilégios brancos em detrimento da existência negra. Esta "concepção institucional do racismo trata o poder como elemento central da dominaçáo" (Almeida, 2018, p. 31). E, ainda que seja menos evidente, por conta da sua sutileza, ele não é menos destrutivo à vida humana.

Carneiro (2011) demonstra a inferioridade social estabelecida pelo racismo na população negra em geral e, particularmente, das mulheres negras. A cor da pele e/ou fenótipo se torna obstáculo central para esses sujeitos ingressarem e permanecerem nas instituiçóes, inclusive naquelas pertencentes à realidade educacional pública e privada do Brasil. Isso se dá sobretudo no Ensino Superior, de forma a manter e condicionar a estrutura e a atuação do Estado, suas instituiçôes e as políticas públicas, produzindo e

\footnotetext{
${ }^{1} \mathrm{O}$ último país das Américas a abolir formalmente o processo de escravização da população negra, sendo importante salientar que a "libertação" dos negros se deu antes por pressão internacional, especialmente pelos ingleses que pressionavam e legitimavam uma imagem negativa do Brasil em razão da continuidade da escravização (Ribeiro, 2019).
} 
reproduzindo uma hierarquia racial na qual negros e negras devem ser mantidos na base dessa pirâmide (Amorim et al., 2020; Góis, 2008).

Dentro desse recorte, se nos referirmos às mulheres negras, são estas as que estão submetidas à situação de maior desvantagem, por sua raça e condição de gênero, no acesso a cursos considerados de maior prestígio social, tal como identificado por Queiroz \& Santos (2016).

Às mulheres negras tradicionalmente têm sido destinadas atividades de menor valoração social. Escravas por alguns séculos, mesmo após libertas não conseguiram alterar de modo pleno o seu status no mundo do trabalho. $\mathrm{O}$ período pós-abolição guardou para elas condiçôes de sobrevivência e trabalho muito precárias. Com baixa ou nenhuma escolaridade e baixíssima remuneração, desenvolviam atividades de ganho em casas de família e nas ruas, sendo com frequência objeto de perseguição policial (Góis, 2008, p. 749).

Nesse contexto, as mulheres negras se tornaram uma grande potência nas discussōes das injustiças sociais no Brasil. Estas começaram a se (re)unir e discutir como a associação desses marcadores sociais e mecanismos de poder perpassam dimensôes macro e micro da vida em sociedade. Questionam o status social da mulher, a sua subordinação - a qual, em diferentes épocas, traz em comum a articulação das opressóes de raça, gênero e classe (vinculadas aos mecanismos de exclusão do racismo, machismo e da pobreza). Reforça-se, assim, a importância histórica de lutas dos Movimentos Negros e de Mulheres de todo o país, tornando o movimento mais representativo ao dar visibilidade às reivindicações das mulheres negras (Collins, 2000; Henning, 2015; Leite Junior et al., 2021).

Nesse sentido, a luta das mulheres negras vem articulando o surgimento de açóes políticas feministas e antirracistas. Conforme Gonzalez (1984) e Akotirene (2018), reafirma-se a importância de uma leitura interseccional, fomentando o debate em torno das desigualdades baseadas nas questóes raciais interpeladas, também, pela questão de gênero e classe. Com base nessas autoras, o não reconhecimento da existência de diferenciaçôes sociais baseadas nestas intersecçóes pode encobrir as vulnerabilidades específicas das mulheres negras, especialmente quando se trata da garantia dos seus direitos.

Desse modo, as noções a partir das quais os marcadores gênero, raça e classe (que podem também estar em intersecção com outros marcadores sociais) são compreendidos e manipulados na sociedade colonialista/capitalista na qual vivemos influenciam diretamente no acesso e na participação social de mulheres negras no Ensino Superior, impondo barreiras ao seu desempenho acadêmico e à permanência na universidade.

Estudos como os de Alcântara \& Silva Junior (2020), Gonçalves (2018), Malpighi et al. (2020) e Queiroz \& Santos (2016) são unânimes em afirmar que, apesar do acesso de mulheres negras à universidade ter aumentado em decorrência das políticas afirmativas, ainda são grandes os desafios enfrentados por estas no cotidiano das relaçóes universitárias. Essas pesquisas revelam que, além das mulheres negras estarem subrepresentadas no Ensino Superior, ainda sofrem com práticas racistas e sexistas em decorrência das representaçóes sociais construídas sobre a mulher em geral e sobre as mulheres negras em particular. 
Assim, ainda há muitas questôes a serem investigadas sobre a participação social de mulheres negras na universidade, de modo a revelar as formas de produção e reprodução de mecanismos racistas no meio acadêmico e seus impactos no cotidiano universitário destas mulheres. Este estudo, especificamente, foi conduzido pelos seguintes questionamentos: Quais as dificuldades enfrentadas por mulheres negras no acesso ao Ensino Superior em uma universidade pública de Alagoas? Há vivências de racismo na trajetória universitária dessas mulheres? Quais apoios e resistências elas mobilizam no enfrentamento do racismo no cotidiano universitário?

Nesse cenário, o objetivo principal foi compreender os impactos do racismo na participação social de estudantes negras na universidade $\mathrm{e}$ as suas formas de enfrentamento, tomando-se a realidade de uma universidade do estado de Alagoas Brasil.

\section{Procedimentos Metodológicos}

Partindo da compreensão de que a sociedade brasileira é marcada por relaçóes desiguais e hierarquizadas, buscamos aqui abordar de forma qualitativa, por meio de uma pesquisa de campo, a realidade de estudantes negras de graduação em uma universidade pública do estado de Alagoas.

Para a produção dos dados, utilizou-se o método do grupo focal, técnica de pesquisa qualitativa que coleta informaçóes por meio das interaçōes grupais. A escolha da técnica se deu pelo fato dela proporcionar um espaço de discussão capaz de ir além dos limites das respostas de um único entrevistado, revelando tanto os significados supostos pelas pessoas no tópico em discussão como a maneira pela qual elas negociam esses significados, gerando diversidade dentro do grupo (Flick, 2009).

A busca de possíveis estudantes se deu de três formas: primeiro, realizaram-se visitas às salas de aula de todos os cursos, visando apresentar o estudo, retirar dúvidas e deixar o contato (e-mail) da pesquisadora; segundo, foi reforçado o convite enviando e-mail para todas as turmas, com a finalidade de receber os dados das possíveis interessadas; terceiro, após o levantamento das estudantes interessadas e de posse do contato delas, realizou-se contato telefônico para confirmar a participação e agendar o grupo focal.

Os critérios de inclusão da pesquisa eram: estudantes matriculadas na instituição, do segundo ao último ano dos cursos bacharelados e tecnológicos, que se reconheciam como mulheres e que se autodeclaravam negras/pretas ou negras/pardas, com 18 anos ou mais e que aceitaram participar, assinando o Termo de Consentimento Livre e Esclarecido (TCLE). Foram excluídas aquelas que atendiam aos critérios de inclusão, mas que, no momento da produção dos dados, estavam com matrícula trancada.

A produção dos dados ocorreu no mês de junho de 2019 e o grupo focal teve duração de 1 h30min, sendo composto por seis estudantes negras - todas matriculadas na modalidade bacharelado - e dois pesquisadores, que se dividiram entre coordenador e secretário do grupo. Para melhor registro das informaçôes, o grupo focal foi gravado em áudio.

Para orientar a discussão, o grupo foi guiado por um roteiro com questôes previamente elaboradas pelos pesquisadores, que serviram de disparadores da interação grupal. Foi aplicado ainda um formulário para coleta de dados, que permitiu traçar um perfil das estudantes, conforme Tabela 1 . 
Tabela 1. Caracterização das estudantes.

\begin{tabular}{cccccc}
\hline Participante & Idade & Período & Cotista & $\begin{array}{c}\text { Pessoas com nível } \\
\text { superior na família }\end{array}$ & $\begin{array}{c}\text { Escola do ensino } \\
\text { médio }\end{array}$ \\
\hline Estudante 1 & 20 & $5^{\circ}$ & Náo & 1 & Pública \\
\hline Estudante 2 & 23 & $8^{\circ}$ & Sim & 1 & Pública \\
\hline Estudante 3 & 20 & $7^{\circ}$ & Náo & 2 & Privada \\
\hline Estudante 4 & 32 & $1^{\text {o }}$ & Sim & 0 & Pública \\
\hline Estudante 5 & 26 & $5^{\circ}$ & Sim & 0 & Pública \\
\hline Estudante 6 & 21 & $7^{\circ}$ & Não & 1 & Privada \\
\hline
\end{tabular}

Fonte: Elaborado pelos autores com base nos dados da pesquisa.

Com o intuito de responder o problema e objetivos da pesquisa, o áudio gravado foi transcrito na íntegra e analisado por meio da técnica de análise temática, de acordo com a perspectiva da Análise de Conteúdo proposta por Bardin (2011). O processo seguiu os seguintes passos: leitura exaustiva do material para identificação das ideias centrais; interpretação dos sentidos de tais ideias; agrupamento das mesmas em categorias; comparaçáo entre os diferentes núcleos de sentido encontrados nas categorias; classificaçáo dos núcleos de sentido em eixos mais abrangentes em torno dos quais giraram as discussões; e redação das sínteses interpretativas de cada tema. A escolha pela análise temática ocorreu pelo reconhecimento da efetividade da técnica, ao se pretender examinar opiniôes, atitudes e crenças, por meio de dados qualitativos.

No processo de análise e construção das categorias, foram consideradas as experiências individuais e coletivas das estudantes. Os dados produzidos foram discutidos e confrontados de forma crítica e reflexiva, com referências teóricas que abordam as questóes centrais da pesquisa, compreendendo que a posição/escolha dessas estudantes implica em tensóes com uma série de normalizaçóes sociais impostas às questôes de gênero, raça, classe e sexualidade.

O estudo foi aprovado pelo Comitê de Ética e Pesquisa com Seres Humanos da universidade, com CAAE n. 11470919.8.0000.5011, e seguiu as recomendaçóes da Resolução CNS 510/16, que regulamenta a pesquisa com seres humanos nas ciências humanas e sociais e, naquilo em que esta é omissa, seguiu as instruçóes da Resolução CNS 466/12, que apresenta normas éticas gerais para realização de pesquisas com seres humanos.

\section{Resultados e Discussáo}

A partir da análise, os resultados e a discussão foram organizados nas seguintes categorias temáticas: 3.1. Dificuldades relacionadas ao acesso e permanência na universidade; 3.2. Expressóes do racismo no cotidiano universitário e 3.3. Estratégias de enfrentamento ao racismo. Estas são apresentadas detalhadamente a seguir.

\section{Dificuldades relacionadas ao acesso e permanência na universidade}

Completados oito anos da sanção da Lei de cotas no Brasil, muitas ainda são as dificuldades de acesso de mulheres negras ao Ensino Superior. Segundo Marcondes et al. 
(2013), esta política de cotas, a partir dos anos 2000, propiciou um crescimento mais acentuado do acesso de afrodescendentes às universidades. Entretanto, para além do acesso, identificamos que um dos principais desafios encontrados pelas estudantes é a sua permanência.

A educação pública é atravessada por grandes desafios. Parte deles se dá pela falta de investimento, o que resulta em fragilidades educacionais que dificultam o acesso ao Ensino Superior de jovens oriundos desta rede educacional. Os dados do Instituto Brasileiro de Geografia e Estatística - IBGE evidenciam que 79,2\% de jovens que frequentaram a rede privada de ensino ingressaram no Ensino Superior em 2017, contra apenas 28,2\% de jovens da rede pública (Instituto Brasileiro de Geografia e Estatística 2018). Dentre as estudantes participantes da pesquisa, quatro cursaram o Ensino Médio na rede pública de ensino (ver Tabela 1) e estas relataram terem encontrado desafios para "acompanhar" os demais alunos.

Em relação até o acompanhamento dos outros colegas por terem estudado em escolas particulares e ter tido cursos, né? Entäo a minha maior dificuldade realmente foi essa. Foi chegar aqui e acompanhar todos (Estudante 4).

Eu sinto dificuldade com relação à escola pública que eu estudei toda a minha vida. Existia a deficiência de algumas disciplinas, e ai chegar até aqui com deficiência em quimica... a gente cursa um ano inteiro de bioquimica... é demais (Estudante 5).

Assim, relatam a necessidade de "correr atrás", caso haja esta falta, para acompanhar os conteúdos da formação graduada, o que exige um esforço individual maior em relação aos demais colegas, assim como relatado na pesquisa de Queiroz \& Santos (2016). Todavia, cabe ressaltar que esta necessidade não ocorre necessariamente por questóes individuais de falta de capacidade, mas devido ao histórico de privaçóes sociais, econômicas e culturais que colocou essas estudantes em posição de desvantagem em relação a grupos mais favorecidos da sociedade, além de um projeto neoliberal de enfraquecimento dos dispositivos públicos, sendo a educação um grande alvo, como afirmam Lusa et al. (2019). Inclusive, apesar desse contexto, pesquisas evidenciaram que estudantes negras e negros, provenientes de açóes afirmativas, superam as adversidades do seu contexto e apresentam desempenho igual ou superior aos demais colegas (Cavalcanti et al., 2019).

A questão econômica também afeta diretamente a participação em atividades que fazem parte da vida acadêmica.

[...] o curso é integral. Então demanda da gente muito tempo e muito dinheiro também para poder se alimentar e passar o dia todo aqui e ainda tem outras atividades extracurriculares que também demandam dinheiro, demandam tempo e essa foi uma das dificuldades que eu encontrei (Estudante 6).

A maioria das estudantes reside em locais distantes da universidade, nas zonas periféricas da cidade ou em outras cidades do estado. À questão financeira, soma-se a necessidade de firmar residência - muitas vezes sem os familiares - na capital. $\mathrm{Na}$ 
tentativa de diminuir os custos, elas passam a lidar com a distância da família, fragilizando suas redes de suporte.

As minhas maiores dificuldades são pelo fato de eu ser do interior e precisar deixar minha familia para morar aqui... Tanto pela questão afetiva, quanto pela questão financeira também (Estudante 1).

Eu sou do interior e vim morar aqui. Entrei com uns dezessete anos [...]. Então, tipo, já é bem barreira mesmo, porque você, dezessete anos, morar em uma capital, sair do interior, vim morar só, começar a se virar sozinha, conciliar os estudos com o cuidado com a casa e tudo (Estudante 3).

[...] a gente vê muitas pessoas negras, como eu, que mesmo não tendo condiçóes financeiras, não conseguem a bolsa por motivos que a gente simplesmente não tem como explicar né? Ano passado comentei com meus amigos próximos que estava pensando em trancar um tempo o curso para poder trabalhar, porque, minha familia, meus pais estavam se separando, então estava passando por dificuldades financeiras e eu não consegui a bolsa de jeito nenhum. Só não parei porque eu consegui uma bolsa do PET (Estudante 6).

Os exemplos citados demonstram como as políticas de permanência estudantil são estratégias fundamentais para diminuir a evasão e garantir a conclusão do curso. Ocorre que, muitas vezes, os recursos são insuficientes, se levarmos em consideração o quantitativo de estudantes em vulnerabilidade social que ingressam todos os anos na universidade. Além do mais, estas políticas se dão de modo diferente nas universidades estaduais e federais. Nas estaduais, os programas são propostos e regulados pelo governo estadual; portanto, as estratégias podem ser completamente diferentes em cada estado. Já nas federais, ainda que existam proposiçôes locais, a permanência estudantil é pautada no Programa Nacional de Assistência Estudantil - PNAES.

Ademais, às marcas da fragilidade financeira, somam-se os desafios de estar sozinha em um novo território, tendo que lidar com as demandas que são assim impostas e com a ausência de uma rede afetiva mais próxima. Inclusive, as políticas de permanência seriam essenciais para maior autonomia das estudantes na construção de novas redes de suporte afetivo e de sociabilidade.

Os discursos das estudantes também chamam atenção para uma possível falta de transparência e organização das políticas existentes, em especial a denominada bolsa permanência, fazendo com que muitas se sintam abandonadas pela própria instituição.

E essa questão da seleção que é feita para os bolsistas, não é uma coisa que a gente sabe mesmo como é feita. Então afeta muito e desmotiva os estudantes de permanecer na faculdade, porque tenta uma oportunidade, se frustra e não consegue. Você cria expectativa de como você poderia continuar com esse dinheiro e acaba não conseguindo e vendo outras pessoas que você sabe que têm condiçóes financeiras muito melhores do que a sua e desfrutam desse dinheiro, como ...é, de maneira aleatória os critérios de acesso às bolsas permanência (Estudante 3). 
A dificuldade em se manter financeiramente e se sentir desprotegida pelos aparatos institucionais de apoio pode contribuir para uma possível evasão e reforçar a ideia de que a universidade é um ambiente destinado a poucos. Conforme identificamos a seguir, as mulheres negras que conseguem continuar no campus, por meio de estratégias informais de permanência, vivenciam dificuldades na sociabilidade, na identificação com seus pares e acabam se sentindo pouco representadas.

E sem contar que na sala, na minha sala, eu não poderia dizer exatamente a quantidade de negros porque a gente não sabe quem se declara negro, né? Mas é uma quantidade minima. É de você olhar e perguntar: onde é que estão os negros? E meio que você já sabe, isso já é uma resposta (Estudante 5).

Falta muita identificação racial mesmo na universidade, aqui principalmente. Uma coisa que a gente sempre conversou, eu e meus amigos é que a gente não se identificava com as pessoas que estão aqui, a gente não se identificava com os nossos professores... só tem uma professora, que ela não se autodeclara negra, mas a sociedade a lê como negra (Estudante 6).

A falta de identificação e representatividade se repete em várias outras falas das entrevistadas, perpassando o sentimento constante de não pertencimento ao espaço universitário. Isto revela o quáo desafiadora a vida acadêmica se torna para as mulheres negras, que cotidianamente são recordadas que aquele espaço, estruturado por modelos brancocêntricos, parece não lhes caber, fenômeno este também citado por Alcântara \& Silva Junior (2020). Todavia, esse desconforto pode mobilizar a formação de pequenos quilombos ${ }^{2}$, a partir da organização coletiva de pessoas negras, criando espaços e momentos para compartilharem suas experiências, trocarem afetos e construírem uma relação de pertença e coletividade, em locais de maioria branca.

Sobre isso, Thomas \& Hollenshead (2001) apontam que as vivências das mulheres negras na universidade estão associadas ao isolamento e marginalização social. Entretanto, esse "não lugar" na academia pode estimular o desenvolvimento de uma unidade de resistência e a produção de um discurso contra-hegemônico. Porém, isso também é uma tarefa com desafios, que pode gerar sobrecarga e que, no geral, fica a cargo dos sujeitos já fragilizados resolvê-la, sem apoio institucional. Sobre isso, uma estudante coloca:

Só que os estudantes precisam se reconhecer e se empolgar com a luta antirracista. Há um tempo queríamos criar um coletivo negro na universidade. Só que é desanimador tentar fazer qualquer coisa do tipo aqui porque os alunos realmente não têm tempo, não têm vontade, acho que força de vontade é a palavra certa, para se envolver realmente com a luta. Mas a gente começa a pensar que esses próprios estudantes estão desmotivados porque as vezes não se reconhecem, ou não

\footnotetext{
2 "Aquilombar-se tem se tornado um termo popular entre grupos negros engajados na ideia de resistência da cultura negra brasileira. Para esses grupos, 'quilombo' é uma importante tecnologia social de resistência que promove o 'estar junto' para ampliar e potencializar saberes, cultura, identidade e histórias ancestrais. Aquilombar-se é, para os negros, um jeito de ser no mundo" (Batista, 2019, p. 399).
} 
veem como uma luta sua, ou estão muito cansados porque também a universidade é massacrante (Estudante 6).

Dessa forma, fica explícito como a ausência de possibilidades de aquilombamento e de políticas de permanência estudantil que se voltem mais largamente às demandas de grupos historicamente marginalizados são uma barreira para a vivência universitária plena. Esta fragilidade nas universidades nos distancia da meta de alcançarmos a reparação histórica e justiça social destes sujeitos. Ainda, a precarização dos espaços destinados a fomentar a discussão étnico-racial, evidencia o racismo presente nas relaçóes institucionais e favorece a invisibilizaçáo das negras e negros na universidade, reforçando o modelo institucional branco e elitista, historicamente hegemônico nas universidades públicas brasileiras.

\section{Expressóes do racismo no cotidiano universitário}

O ambiente acadêmico por vezes se mostra como um local hostil e segregador para as estudantes negras. As experiências de preconceito e discriminação vivenciadas por elas se manifestam, em sua maioria, de forma velada, através de olhares ou modos de tratamento, seja nos corredores da universidade ou em locais onde ocorrem aulas práticas e estágios.

Preconceito revelado, de uma forma que me deixasse mal eu não cheguei a vivenciar, só que às vezes só o olhar, não precisa ser só palavras né?, mas basta um olhar diferenciado, porque eu gosto de utilizar algumas coisas no meu cabelo, porque eu vivo mudando meu cabelo (Estudante 4).

"Me doeu muito o fato de no primeiro dia eu chegar lá [local de estágio] com as tranças e os profissionais começaram a me olhar estranho. Me julgando por olhares, elas me olhavam e começavam a comentar umas com as outras. E... nossa, eu falando assim ... [choro] parece bem forte porque eu não comentei com ninguém, para algumas pessoas pode ser alguma coisa bem minima, de só estarem olhando para você, mas que para a gente afeta muito (Estudante 3).

Ao serem definidas socialmente por meio de seus traços fenotípicos, quanto mais essas mulheres negras, em espaços como a academia, expuserem sua negritude por meio das vestimentas, do cabelo ou de outros meios relacionados à aparência física, parece que maior será a discriminação e sujeição a situaçóes de racismo. Isso se aplica também para a cor da pele: quanto maior o pigmento de melanina, maiores são os processos de exclusão e depreciação, sendo a pessoa negra mais tolerável quando a sua pele é mais clara (Nascimento, 2015).

Além dos olhares, as estudantes também relataram como o racismo também se apresenta através de linguagem jocosa - as ditas "brincadeiras", "piadas de preto" -, que nem sempre assume a forma de violência declarada, ou seja, não se associa diretamente a situaçôes de conflito aberto. Esta dimensão é definida e discutida por Moreira (2019) como racismo recreativo, conceito que diz respeito a uma política cultural que utiliza o humor racista para expressar hostilidade em relação às minorias raciais. Essas "piadas", no contexto da pesquisa, são proferidas não somente por parte de estudantes, nos 
corredores e espaços de convivência, mas também se apresentam em sala de aula, por vezes protagonizada pelos próprios professores.

Piadinhas muito sutis. É claro que hoje em dia até de uma forma mais suave, mas eu acredito que no inicio, assim que eu ingressei na universidade, até pessoas próximas mesmo de acharem que uma piadinha é normal (Estudante 2).

Eu acho que fere mais quando um professor que é autoridade, espelho, entra nesse meio de piadas. Basicamente você está dando um "direito" de os alunos também entrarem nesse meio. Pelo menos eu já presenciei em sala de aula alguns professores usando navio negreiro como exemplo para dar aula, tipo, como assim? Para dar um exemplo de fisica (Estudante 3).

As "piadas" mencionadas vão além da condição do negro na sociedade e se referem também à questão de gênero. A presença feminina no meio científico ainda é marcada pelo sexismo. Os discursos raciais passam a ter influência dos marcadores sociais de gênero, correlacionando-se. Em consonância com Spivak (2010) e Akotirene (2018), esses comentários são assegurados em um sistema de poder que inferioriza, invisibiliza e impede a produção de saberes de grupos considerados subalternos.

Além de racista, também machistas na sala de aula e o que mais feria era o fato de a gente comentar, entrar em debate, discutir que isso não deveria acontecer, que isso é errado e outras pessoas dizerem "náo, é só vocês saberem lidar com a pessoa, rir das piadas que ele fala que passa". E tem pessoas que concordam para poder passar na disciplina e náo serem afetadas por esse professor (Estudante 3).

O silenciamento reforça a ideia de não pertencimento das mulheres negras no ambiente acadêmico, subjugando sua capacidade e lhes negando direitos já conquistados. Como uma das estudantes afirma, "a gente é, muitas vezes, ignorada" (Estudante 5). Tais situaçóes geram uma pressão pela excelência, ter que ser mais, esforçar-se mais que os demais para ter reconhecimento no espaço acadêmico, sentimento este também relatado pelas participantes do estudo de Queiroz \& Santos (2016).

É como se a gente tivesse que fazer o esforço dobrado para chamar atenção, para ter um destaque em algo, que o professor elogie, que ele diga que você vai participar de um projeto, um grupo de pesquisa, oportunidades. Já passei por situaçóes em que o professor, antes de dar a minha nota, ele olhar, ele não tinha olhado a de ninguém. Ai quando chegou na minha vez ele deu uma conferida, para ver se tinha sido boa. Ai balançou a cabeça assim e devolveu. Então eu não entendi né? Por que olhar a minha nota? Só a minha nota? (Estudante 5).

Acontece muito, entre os professores, deles darem mais atenção a quem é branco, a quem é homem (Estudante 3).

[...] e quando os professores veem você com uma dupla... Uma mulher negra está em uma dupla com um homem, fazendo dupla com um homem branco, ou um homem negro as vezes, uma dupla de prática, o professor sempre vai falar com o 
homem. Gente, é incrivel como o professor sempre vai falar com o homem, e até mesmo os pacientes subestimam você (Estudante 6).

Nesse sentido, construiu-se um mito de hierarquização de saberes, resultado de uma classificação racial que atribui aos negros falta de capacidade intelectual e de desempenho. Com isso, mulheres negras a todo instante têm que provar que são capazes de exercer funçóes diferentes e ocupar esses espaços. Gonzalez (1984) afirma que existe um modelo valorizado de se fazer ciência na modernidade e esse modelo é branco. Assim, quem detém o privilégio social possui o privilégio epistêmico.

Hooks (1995, p. 468) aponta o fato da mulher negra culturalmente náo ser ligada ao ato de pensar, de produzir ciência; estão ligadas à objetificação e sexualização do corpo, o que faz com que "[...] sejamos intrusas para colegas de perspectivas estreitas". Desse modo, faz-se correlação desse não lugar da mulher negra na ciência, na produção de conhecimento, com os aspectos culturalmente construídos sobre o seu papel social. Como resquícios do período escravocrata, o senso comum, até os dias atuais, aprisiona e associa as mulheres negras aos trabalhos domésticos, aos serviços da casa grande e aos serviços sexuais, como no relato a seguir:

Uma vez eu precisei vir com meu sobrinho que é adotado, ele é loiro. Na época ele tinha 3 anos, foi no meu primeiro ano de faculdade e eu vim tirar uma xerox aqui na universidade. Quando eu passei pela portaria, um dos vigilantes perguntou se já não bastava a gente ocupar os espaços que náo eram para a gente e para se manter ali dentro precisava cuidar dos filhos de professores (Estudante 1).

Os relatos demonstram a difícil tarefa que mulheres negras enfrentam para superar a imagem servil que lhes foi atribuída, historicamente, com base em sua cor, gênero, classe e sexualidade, muitas vezes não importando o espaço que elas ocupem, seu trabalho e nem a trajetória intelectual. Gonzalez (1984) já afirmava que não adianta serem "educadas", ou estarem "bem vestidas", ainda assim, serão obrigadas pelo porteiro a entrarem pela porta de serviço.

Eu tentei por muito tempo não querer acreditar que as pessoas tratassem alguém diferente por causa da cor e da classe social. Porque se for olhar, a maioria dos negros da universidade é de classe baixa (Estudante 5).

O tratamento recebido devido à sua cor, associado à sua classe, expóe um fenômeno muito peculiar no Brasil: o mito da democracia racial, o qual teve como maior expoente intelectual Gilberto Freyre (1933), com a obra "Casa Grande \& Senzala”. Essa crença, como discute Fernandes (2011), náo tem consistência e favorece o encobrimento do preconceito racial em relação à população negra, alimentando um discurso que propaga a existência de uma relação harmoniosa e igualitária entre brancos e negros. Isto não corresponde às situaçóes concretas que a população negra vivencia. A sociedade prédetermina quais são as possibilidades e os espaços da mulher negra e a educaçáo surge como uma possibilidade de subversão, possibilitando-a ocupar espaços outros, tidos como não pertencentes a ela. Possibilita ainda ingressar no mercado de trabalho, galgando cargos de prestígio, e obter melhor condição financeira. 
Desse modo, considerar a interseccionalidade de gênero, raça, classe, sexualidade e a universidade como possibilidade de transformação social evidencia a importância da ampliação do debate sobre a ascensáo das negras e negros, a partir das oportunidades de acesso ao Ensino Superior.

\section{Estratégias de enfrentamento ao racismo}

Reconhecendo os impactos subjetivos e objetivos do racismo no cotidiano das estudantes, foi lhes questionado sobre as estratégias pessoais utilizadas para lidarem com o racismo no espaço universitário, como também sobre quais seriam as melhores medidas institucionais para lidar com a questão.

No que diz respeito às estratégias pessoais, a maioria destaca o apoio afetivo da rede de amigos.

Quando você vai falar com seus amigos, eles se sentem da mesma forma, e um ajuda o outro, mas cada um sangrando da sua forma (Estudante 6).

Eu coloquei tranças no cabelo. Até estava conversando com as colegas que eu estava preocupada porque tinha prática no hospital e a gente tinha que usar touca e não dava para amarrar e colocar a touca assim. As meninas da prática decidiram atender sem toucas porque elas sabiam que eu não teria como colocar também. Eu fiquei feliz com a atitude das minhas amigas (Estudante 3).

Na universidade, em meio a situaçóes discriminatórias, elas relatam precisar ter forças e silenciar, guardar algumas situaçóes para si. Para Prestes \& Paiva (2016), o simbolismo da palavra "força" que se projeta nas mulheres negras é encenado por elas em sua luta cotidiana.

[...] foi muito triste para mim esse dia, mas eu não cheguei a comentar com ninguém. E por mais que eu pudesse comentar com qualquer amigo, e eu teria esse apoio deles, às vezes a gente precisa se guardar em algumas situaçōes. Ser forte (Estudante 3).

As estudantes precisam construir uma identidade centrada em valores positivos, reorganizando em seu imaginário a sua condição de mulher negra na sociedade. Exigese delas força para lidar com as situaçôes de sofrimento, reforçando o imaginário social que as enxerga como mais resistentes a sentir dores (Kreling et al., 2014). Por trás disso, revela-se mais uma faceta do racismo que desumaniza estas pessoas, tendo em vista que essa ideia racista priva a mulher negra de chorar, debater acerca do que a incomoda e a pedir ajuda quando necessita.

Contudo, parte dessa necessidade de "ser forte" e do silenciamento em situaçóes discriminatórias e de sofrimento pode também estar relacionada à fragilidade da assistência estudantil, aqui representadas nos canais institucionais de apoio, como a ouvidoria e o apoio psicopedagógico, entre outros dispositivos que acabam acolhendo de maneira fragmentada as demandas estudantis, deixando de fora aspectos essenciais que perpassam as dificuldades de estudo, por exemplo, o racismo. 
A gente pode ir ao psicólogo conversar isso, mas a maioria dos psicólogos daqui da universidade está ali para poder manter você na universidade, em questáo de estudo. O apoio psicopedagógico não consegue atender nossa demanda (Estudante 3).

Mas existem coisas aqui dentro, no sistema, que não funcionam como deveria funcionar. A gente não é atendida como deveria. E eu procurei apoio, eu fui à ouvidoria, fiz uma denúncia e não tive retorno nenhum (Estudante 1).

Além disso, as estudantes apontam a necessidade de espaços no campus para se sentirem representadas, espaços que proporcionem discussão e reflexão sobre a questão do negro nos campos da política e da formação universitária, como forma de combater o preconceito e a discriminação racial.

Eu acho que a universidade deveria procurar criar, incentivar mais os estudantes a fazerem parte desses espaços de autorreconhecimento e de enfrentamento (Estudante 6).

Acho muito válido a questão de seminários, organizar eventos, oficinas, algo que traga mesmo a questão da cultura negra (Estudante 4).

Conforme apontado anteriormente sobre o aquilombamento, estes espaços podem ser vistos como uma importante estratégia de cuidado, favorecendo a autoafirmação e aceitação da sua identidade como mulher negra, bem como possibilitando a criação de estratégias coletivas para o enfrentamento cotidiano do racismo.

Essa questão de aceitação é muito válida. Porque a partir do momento em que você se aceita, você passa a ter uma visão diferente, aquelas opinióes que te bombardeiam agora já não fazem tanto efeito (Estudante 4).

Segundo Hooks (2013), a sala de aula pode ser um espaço potencializador para oferecer possibilidades radicais na academia. Isso inclui criar formas de repensar a educação enquanto formação de valores e saberes ancestrais e enfrentar o racismo por meio de estratégias de valorização e pertencimento étnico-racial. Para isso, as estudantes sugerem investimentos institucionais voltados para a educação permanente e formação profissional dos diferentes servidores.

Cadê a educação desses professores? Cadê a educação permanente? Isso que falta para eles entenderem que aquilo que estão fazendo é discriminação (Estudante 3).

E a universidade também precisa tentar ao máximo educação permanente com professores e servidores em geral. Porque não são só os professores que têm falas racistas, são seguranças, pessoas dos serviços gerais, administração (Estudante 6)

Relatam também a ausência de apoio na elaboração de propostas de pesquisas que abordem as questóes racial e de gênero como foco principal. Isto evita trazer à tona as problemáticas que escancaram as negligências institucionais com essas questóes, 
colaborando para manutenção do racismo e evidenciando, mais uma vez, o despreparo dos educadores sobre estas temáticas.

Incentivo, muito incentivo a pesquisas como essas porque eu não lembro de ter ouvido falar em pesquisas, outras pesquisas de TCC como essa. Na verdade, eu só sei de outra que não foi um TCC relacionado a questão da negritude e não era nem com pessoas, era com relação a grade curricular. Eu tive uma ideia e falaram não, você não vai falar sobre isso porque não tem nada a ver, escolha outro tema para o seu TCC (Estudante 6).

Além das questôes já citadas, elas pontuam a necessidade da criação e maior efetividade das políticas de acesso e manutenção de negros na universidade, como uma forma de enfrentar o racismo.

Em relação as políticas de inserção do negro na universidade e manutenção. Eu acho que é o que falta aqui, porque apesar de ser uma universidade pública, não tem cotas raciais, só tem cotas sociais, que já contribui para ter pouquissimos negros aqui (Estudante 6).

Embora a universidade seja um espaço de manifestaçóes de preconceito e discriminação, ela também proporciona momentos de auto identificação que permitem às estudantes negras a retomada da identidade étnico-racial como uma fonte de orgulho. Prestes \& Paiva (2016) apresentam a ideia da existência resiliente, que se configura como uma importante forma de resistência e enfrentamento das adversidades encontradas pelas mulheres negras no Brasil, a capacidade de ressignificar e superar as vivências desintegradoras.

Cheguei aqui na universidade usando produto quimico no cabelo, bastante quimica, era uma opção minha naquela época, queria seguir um padrão, eu fugia da minha naturalidade, daquilo que me faria bem. Eu passei a enxergar a partir do momento que eu ingressei na universidade, acho que me encontrei aqui. E isso foi o maravilhoso. Eu cheguei aqui com 27 anos, hoje eu tenho 32 anos, e se encontrar de verdade, sair daquele padráo que predomina, que cobram que você tem que vivenciar. Então na academia eu meio que me libertei. Me deixei levar pelo que eu me sentia bem, a partir de coisas que eu vivi aqui dentro, por meio de disciplinas que eu participei (Estudante 4).

A universidade, apresentada como um ambiente branco e, por vezes, hostil para aqueles que não se encaixam no padrão normalizador, também se mostra como um espaço de luta e resistências protagonizadas pelas estudantes negras. Tais atitudes não se limitam às estratégias de enfrentamento ao racismo, mas se ampliam na luta e no compromisso com a busca e efetivaçáo dos direitos das mulheres negras para que saiam do silenciamento e da invisibilização e possam ser ouvidas, exigindo que a universidade assuma a sua responsabilidade com a inserção e manutenção desta população em todos os seus setores. 


\section{Consideraçóes Finais}

$\mathrm{Na}$ última década, houve um aumento significativo na presença e visibilidade de mulheres negras em espaços que, por muito tempo, foram tidos como inalcançáveis. Concomitantemente, deu-se o fortalecimento e maior publicização do feminismo negro no Brasil, com intelectuais negras ocupando espaços acadêmicos e lugares de prestígio social.

Apesar de, até os dias atuais, as universidades se manterem enquanto instituição elitista e segregadora, também se tornaram espaços de transgressão, potencializadores de ascensão da comunidade negra. Apostar na educação como estratégia para ressignificar situaçóes de discriminação e pensar novos modelos educacionais são caminhos utilizados por políticas afirmativas que almejam a busca de justiça social para grupos historicamente subalternizados. Estes aspectos foram enfatizados no discurso e vivências das estudantes que participaram deste estudo.

Ao analisar os aspectos relativos ao racismo, constatou-se que todas as estudantes vivenciaram ou presenciaram alguma situação de preconceito ou discriminação no âmbito universitário, somadas ao sexismo e classicismo. Todo esse contexto reitera os mecanismos de perpetuaçáo existentes para manter a universidade como um espaço branco, racista e elitista. Exige-se dessas estudantes esforços múltiplos, na condição de mulheres negras, para saírem da invisibilidade social em que foram colocadas.

Os resultados deste estudo evidenciam a importância da inserção de políticas afirmativas de recorte étnico-racial nas universidades, o que favorecerá a ampliação do acesso de negras e negros ao Ensino Superior, como também de manutenção destes na trajetória universitária, aspectos essenciais na luta em prol da reparação histórica junto a estes sujeitos. A aposta em ampliar espaços de debates acerca da temática e a educaçáo permanente para servidores das universidades são estratégias institucionais que podem minimizar o problema. Entretanto, destaca-se a importância de fortalecer os canais institucionais e de apoio já existentes nas universidades, considerando o critério racial, visando reduzir as desigualdades no ambiente universitário.

Apesar da riqueza das informaçóes levantadas, reconhecemos os limites do estudo, no sentido de ter sido realizado com um grupo de estudantes de apenas três dos dez cursos da instituição. Questionamos se o fato de não haver voluntárias dos demais cursos estaria relacionado a: ausência de mulheres que se autodeclarem negras; insegurança em falar sobre o tema diante dos mecanismos sociais e institucionais de invisibilizaçáo da mulher negra; e/ou pouca importância dada por elas à temática da pesquisa atrelada à reprodução do discurso hegemônico sobre a produção de conhecimento. Novos estudos sobre a participação social de mulheres negras no âmbito universitário são sugeridos, podendo-se estabelecer comparativos com pesquisas sobre a problemática em cursos de outras áreas ou com instituiçóes de ensino que adotam políticas afirmativas de acesso e permanência universitária com recorte étnico-racial.

\section{Referências}

Akotirene, C. (2018). O que é interseccionalidade? Belo Horizonte: Letramento.

Alcântara, M. S., \& Silva Junior, P. R. (2020). Uma investigação sobre as trajetórias de mulheres negras na universidade pública. Revista AMAzônica, 25(2), 127-163. Recuperado em 27 de maio de 2021, de https://periodicos.ufam.edu.br/index.php/amazonica/article/view/7767 
Almeida, G. E. S., \& Alves, C. M. C. (2011). Educação escolar de mulheres negras: interdições históricas. Revista Educação em Questão, 41(27), 81-106. Recuperado em 15 de julho de 2019, de https://periodicos.ufrn.br/educacaoemquestao/article/view/4003

Almeida, S. L. (2018). O que é racismo estrutural? Belo Horizonte: Letramento.

Amorim, S. G., Martins, S., Leite Junior, J. D., \& Farias, M. N. (2020). “Asfixias sociais” da população negra e questóes para a Terapia Ocupacional. Revista Interinstitucional Brasileira de Terapia Ocupacional, 4(5), 719-733.

Bardin, L. (2011). Análise de conteúdo. São Paulo: Ediçôes 70.

Batista, P. C. (2019). O quilombismo em espaços urbanos: 130 após a abolição. Revista Extraprensa, 12, 377-396. https://doi.org/10.11606/extraprensa2019.153780.

Brasil. (2012, 29 de agosto). Lei no 12.711, de 29 de Agosto de 2012. Dispóe sobre o ingresso nas universidades federais e nas instituiçôes federais de ensino técnico de nível médio e dá outras providências. Diário Oficial [da] República Federativa do Brasil, Brasília.

Carneiro, L. A. V., \& Bridi, F. R. S. (2020). Políticas Públicas de Ensino Superior no Brasil: um olhar sobre o acesso e a inclusão social. Revista IberoAmericana de Estudos em Educação, 15(1), 146-158. Recuperado em 15 de julho de 2020, de https://periodicos.fclar.unesp.br/iberoamericana/article/view/12059

Carneiro, S. (2011). Enegrecer o feminismo: a situação da mulher negra na América Latina a partir de uma perspectiva de gênero. Recuperado em 10 de junho de 2020, de https://www.geledes.org.br/enegrecero-feminismo-situacao-da-mulher-negra-na-america-latina-partir-de-uma-perspectiva-de-genero/

Cavalcanti, I. T. N., Andrade, C. S. M., Tiryaki, G. F., \& Costa, L. C. C. (2019). Desempenho acadêmico e o sistema de cotas no ensino superior: evidência empírica com dados da Universidade Federal da Bahia. Avaliação, 24(1), 305-327. Recuperado em 20 de julho de 2020, de https://www.scielo.br/pdf/aval/v24n1/1982-5765-aval-24-01-305.pdf

Christillino, C. L. (2015). O homem livre e pobre no Brasil oitocentista. In T. B. B. Oliveira (Ed.), Trabalho e trabalhadores no Nordeste: análises e perspectivas de pesquisas históricas em Alagoas, Pernambuco e Paraíba (pp 57-84). Campina Grande: EDUEPB.

Collins, P. H. (2000). Black Feminist Thought. Knowledge, Consciousness, and the Politics of Empowerment. New York: Routledge.

Fernandes, F. (1965). A integração do negro na sociedade de classes. São Paulo: Dominus.

Fernandes, F. (2011). O negro no mundo dos brancos. São Paulo: Global.

Flick, U. (2009). Introdução à pesquisa qualitativa. Porto Alegre: Bookman.

Freyre, G. (1933). Casa Grande \& Senzala. Rio de Janeiro: Maia \& Schimdt.

Góis, J. B. H. (2008). Quando raça conta: um estudo de diferenças entre mulheres brancas e negras no acesso e permanência no ensino superior. Revista Estudos Feministas, 16(3), 743-768. Recuperado em 10 de junho de 2020, de https:/www.scielo.br/pdf/ref/v16n3/02.pdf

Gonçalves, R. (2018). A invisibilidade das mulheres negras no ensino superior. Poiésis, 12(22), 350-367. Recuperado em 27 de maio de 2021, de http://www.portaldeperiodicos.unisul.br/index.php/Poiesis/article/view/7358

Gonzalez, L. (1984). Racismo e sexismo na cultura brasileira. Revista de Ciências Sociais Hoje, 223-244. Recuperado em 06 de março de 2020, de https://edisciplinas.usp.br/pluginfile.php/4584956/mod_resource/content/1/06\%20\%20GONZALES\%2C\%20L\%C3\%A9lia\%20\%20Racismo_e_Sexismo_na_Cultura_Brasileira\%20\%281\%29.pdf

Henning, C. E. (2015). Interseccionalidade e pensamento feminista: as contribuiçôes históricas e os debates contemporâneos acerca do entrelaçamento de marcadores sociais da diferença. Mediaçōes, 20(2), 97-128. Recuperado em 20 de maio de 2020, de http://www.uel.br/revistas/uel/index.php/mediacoes/article/view/22900

Hooks, B. (1995). Intelectuais Negras. Revista Estudos Feministas, 3(2), 464-478. Recuperado em 13 de setembro de 2019, de https://periodicos.ufsc.br/index.php/ref/article/view/16465/15035 
Hooks, B. (2013). Ensinando a transgredir: a educação como prática de liberdade. São Paulo: WMF Martins Fontes.

Instituto Brasileiro de Geografia e Estatística - IBGE. (2018). Sintese de indicadores sociais: uma análise das condiçōes de vida da população brasileira: coordenação de população e indicadores sociais. Rio de Janeiro: IBGE.

Jesus, R. E., \& Gomes, N. L. (2014). A “constituição” da nação brasileira em disputa: o debate em torno da (in) constitucionalidade das açôes afirmativas. Revista TOMO, (24), 85-107. Recuperado em 5 de julho de 2020, de https://seer.ufs.br/index.php/tomo/article/view/3186

Kreling, M. C. G. D., Pimenta, C. A. M., \& Garanhani, M. L. (2014). A discriminação racial no tratamento da dor. Revista Dor, 15(3), 230-235. Recuperando em 9 de abril de 2021, de https://www.scielo.br/pdf/rdor/v15n3/pt_1806-0013-rdor-15-03-0230.pdf

Leite Junior, J. D., Farias, M. N., \& Martins, S. (2021). Dona Ivone Lara e terapia ocupacional: devirnegro da história da profissão. Cadernos Brasileiros de Terapia Ocupacional, 29, e2171. http://dx.doi.org/10.1590/2526-8910.ctoARF2171.

Lusa, M. G., Martinelli, T. M., Samara, A., \& Almeida, T. P. (2019). A Universidade pública em tempos de ajustes neoliberais e desmonte de direitos. Revista Katálysis, 22(3), 536-547.

Malpighi, V. C. S., Barreyro, L. A. L., Marigliano, R. X., \& Leopoldo, K. (2020). Negritude feminina no Brasil: uma análise com foco na educação superior e nos quadros executivos empresariais. Revista Psicologia Política, 20(48), 325-338. Recuperado em 27 de maio de 2021, de http://pepsic.bvsalud.org/scielo.php?script=sci_arttext\&pid=S1519-549X2020000200006\&lng=pt\&tlng=pt

Marcondes, M. M., Pinheiro, L., Queiroz, C., Querino, A. C., \& Valverde, D. (2013). Dossiê mulheres negras: retrato das condiçóes de vida das mulheres negras no Brasil. Brasília: IPEA.

Moreira, A. (2019). Racismo Recreativo. São Paulo: Polén.

Nascimento, G. X. C. (2015). Os perigos dos Negros Brancos: cultura mulata, classe e beleza eugênica no pós-emancipação (EUA, 1900-1920). Revista Brasileira de História, 35(69), 155-176. Recuperando em 9 de abril de 2021, de https://www.scielo.br/pdf/rbh/v35n69/1806-9347-rbh-35-69-00155.pdf

Paixão, M., Rosseto, I., Montovanele, F., \& Carvano, L. M. (2010). Introdução. In M. Paixão, I. Rosseto, F. Montovanele \& L. M. Carvano (Eds.), Relatório anual das desigualdades raciais no Brasil: 2009-2010 (pp. 26-34). Rio de Janeiro: Editora Garamond.

Prestes, C. R. S., \& Paiva, V. S. (2016). Abordagem psicossocial e saúde de mulheres negras: vulnerabilidades, direitos e resiliência. Saúde e Sociedade, 25(3), 673-688. Recuperando em 20 de julho de 2020, de https:/www.scielo.br/pdf/sausoc/v25n3/1984-0470-sausoc-25-03-00673.pdf

Queiroz, D. M., \& Santos, C. M. (2016). As mulheres negras brasileiras e o acesso à educação superior. Revista da FAEEBA - Educação e Contemporaneidade, 25(45), 71-87. Recuperado em 27 de maio, de https://www.revistas.uneb.br/index.php/faeeba/article/view/2286

Ribeiro, D. (2019). Pequeno manual antirracista. São Paulo: Companhia das Letras.

Rodrigues, G. M. (2011). Ensino privado: a qualidade e a imagem. In S. S. Colombo \& G. M. Rodrigues (Eds.), Desafios da gestão universitária contemporânea (pp. 43-58). Porto Alegre: Penso.

Roubião, A. (2013). História da universidade: genealogia pra um “modelo participativo”. Coimbra: Almedina.

Spivak, G. (2010). Pode o subalterno falar? Belo Horizonte: Editora UFMG.

Thomas, G. D., \& Hollenshead, C. (2001). Resisting from the margins: the coping strategies of Black women and other women of color faculty members at a research university. The Journal of Negro Education, 70(3), 166-175.

\section{Contribuiçáo dos Autores}

Ana Cristina de Oliveira Valério: Redação do texto, coleta, sistematização e análise dos dados. Waldez Cavalcante Bezerra: Orientação, análise dos dados e revisão de texto. Os demais autores contribuíram com as 
discussões e revisão final do texto. Todos os autores são responsáveis pela redação do texto e aprovaram a versão final do texto.
Autor para correspondência
Waldez Cavalcante Bezerra
e-mail: waldezto@yahoo.com.br

\section{Editora de seçáo}

\section{Profa. Dra. Ana Paula Serrata Malfitano}

